\title{
"NOVA POLÍCIA" E O PROCESSO INSTITUINTE: CONCEPÇÕES ACERCA DA INSERÇÃO DE MULHERES NO POLICIAMENTO PARANAENSE
}

DOI: 10.22289/2446-922X.V5N1A11

Daniela Cecilia Grisoski ${ }^{1}$

\section{RESUMO}

O trabalho aqui apresentado trata-se de um estudo teórico, cujo objetivo principal consistiu em realizar uma articulação entre a forma em que ocorreu a inserção de mulheres à Polícia Militar do estado do Paraná (PMPR), em meados de 1970, e as concepções teóricas de Gregório Baremblitt (2002) sobre a Análise Institucional, em especial compondo problematizações sobre os conceitos de processos por ele denominados instituídos e instituintes, dentro da linha teórica em questão. O presente trabalho se deu através de uma pesquisa exploratória, tomando como ponto de partida materiais selecionados conforme o objetivo, sendo estes materiais publicações oficiais e não oficiais referentes a inserção de mulheres na Polícia Militar do estado do Paraná, bem como a obra "Compêndio da Análise Institucional e outras correntes: teoria e prática" publicada por Baremblitt (2002). O estudo teórico também se enquadra no campo denominado Relações de Gênero, compreendendo uma análise de papéis sociais que são tidos como, historicamente, denominados para um gênero específico, como é o caso do homem e da mulher inseridos nas organizações da instituição Segurança Pública. Compreendeu-se a entrada de mulheres na organização Polícia Militar do Paraná como uma desconstrução de modelos préestabelecidos, visto que esta era tida como uma organização unicamente masculina, cujos trabalhos dos policiais deveriam ser executados apenas por profissionais do sexo masculino. Desta forma, modificaram-se algumas lógicas as quais estavam cristalizadas na mesma. Por outro lado, a reprodução de um discurso masculino dominante continua em evidência, propondo uma divisão de funções de gênero.

Palavras-chave: Relações de gênero; Análise institucional; Instituição Militar.

\section{ABSTRACT}

The paper presented here is a theoretical study whose main objective was to articulate the way in which the insertion of women into the Military Police of the state of Paraná (PMPR) occurred in the mid 1970s, and the theoretical conceptions of Gregório Baremblitt (2002) on

${ }^{1}$ Endereço eletrônico de contato: grisoskidaniela@gmail.com

Recebido em 07/01/2019. Aprovado pelo conselho editorial para publicação em 26/01/2019.

Rev. Psicol Saúde e Debate. Jul., 2019:5(1):132-143. 
Institutional Analysis, especially composing problematizations about the concepts of processes that he called instituted and instituting, within the theoretical line in question. The present work was done through an exploratory research, taking as starting point materials selected according to the objective, these materials being official and unofficial publications referring to the insertion of women in the Military Police of the state of Paraná, as well as the work "Compendium of the Institutional Analysis and other currents: theory and practice "published by Baremblitt (2002). The theoretical study also falls within the field called Gender Relations, comprising an analysis of social roles that are considered as historically named for a specific gender, as is the case of men and women inserted in the organizations of the Public Safety institution. It was understood that the entry of women into the Military Police of Paraná as a deconstruction of pre-established models, since this was considered as a solely male organization, whose work of the police should be performed only by male professionals. In this way, some logics were modified which were crystallized in it. On the other hand, the reproduction of a dominant masculine discourse remains in evidence, proposing a division of gender functions.

Keywords: Gender relations; Institutional analysis; Military Institution.

\section{INTRODUÇÃO}

O presente trabalho se caracteriza como um estudo teórico, sendo parte do processo de desenvolvimento de uma dissertação, iniciada em 2018, em um Programa de Pós-Graduação em Psicologia. Como objetivo central, o trabalho em questão visa articular uma relação entre a forma em que se deu a inserção de mulheres à Polícia Militar no estado do Paraná, em meados da década de 1970, a partir das concepções teóricas de Gregório Baremblitt sobre a Análise Institucional, em especial compondo problematizações sobre os conceitos de processos por ele denominados instituídos e instituintes, dentro da linha teórica em questão.

Gregório Baremblitt, renomado teórico da América Latina, nasceu na Argentina, mudando-se para o Brasil na década de 1970, após a instauração de uma ditadura militar em seu país de origem, tornando-se, posteriormente, um dos maiores pensadores do campo da Análise Institucional (Hur, 2014). Por sua vez, a abordagem denominada Análise Institucional, de acordo com L'Abbate (2003), tem a característica de desenvolver conjuntos de conceitos e instrumentos visando analisar e intervir em instituições. No Brasil, a Análise Institucional começou a se destacar por volta da década de 1970, a partir de pesquisas em universidades com profissionais de variadas áreas.

A Análise Institucional não possui um caráter único, pois é formada a partir de um conjunto de disciplinas, as quais se iniciaram por volta das décadas de 1940 a 1950 na sociedade francesa. Tais disciplinas têm o intuito de problematizar a constituição de um campo institucional como um conjunto de saberes e práticas em um contexto amplo, enquadrados em uma ordem político-social, ideológica e técnico-científica (L’abbate, 2003).

Baremblitt (2002) caracteriza o chamado movimento institucionalista enquanto um leque de tendências que não são unilaterais, mas sim possuem um objetivo em comum: apoiar os 
processos de autoanálise e autogestão de um meio social. Os processos de autoanálise e autogestão, compreendem a organização de uma sociedade para produzir saberes e dispositivos necessários para a manutenção e melhoramento sobre a vida dos indivíduos. Nestes processos, existe uma hierarquia de pessoas através de suas capacidades de produção, mas não há a hierarquia de poder, em que um sujeito se sobressai o outro.

O autor ainda aponta que os saberes que vigoram em uma população vem sendo produzidos através sujeitos que são denominados como experts, pois possuem 0 aperfeiçoamento sobre determinado assunto. Esses experts são compreendidos como os conhecedores de uma sociedade, que influenciam os modos de vida dos cidadãos (Baremblitt, 2002).

Abarcando concepções sobre o que é uma instituição, Baremblitt (2002), ressalta que uma instituição se caracteriza como um conjunto de lógicas e leis que compõem determinado valor social, sendo essas lógicas abstratas. Por sua vez, quando as instituições se constituem através de uma estrutura material, passam a ser chamadas de organizações. Na perspectiva em que este trabalho foi desenvolvido, a lógica que o compõe é a Segurança Pública, sendo esta uma instituição. Tendo em vista ainda, que a organização a qual destacamos é a da Polícia Militar.

Ainda considerando as lógicas que compõem a Análise Institucional, um estabelecimento surge como as estruturas específicas as quais se enquadram dentro de uma determinada organização, sendo esta, em nossa pesquisa e nestas páginas, a Polícia Militar do estado do Paraná, em específico.

A configuração de um estabelecimento conta com equipamentos, consistindo em materiais, objetos ou dispositivos os quais se organizam para a constituição de um local. Também conta com os agentes, que por sua vez são descritos como os profissionais atuantes em um determinado estabelecimento. Neste caso, os agentes compreendem-se como policiais militares femininas da instituição em questão, as quais desenvolveram suas trajetórias laborais dentro da Polícia Militar do Paraná por volta dos anos 1970, época em que houve a inserção de mulheres nessa organização (Governo do Paraná, 1977). Por sua vez, os equipamentos disponíveis foram caracterizados pelas fardas, armas e outros objetos destinados aos policiais militares da época em questão (Baremblitt, 2002).

Compreendendo o atual cenário político e econômico em que nossa sociedade se encontra, em que casos de violência urbana vêm frequentemente se destacando, a Polícia Militar Feminina em específico foi tomada enquanto ator de análise, considerando que as lógicas que compõem esta organização estão no contexto de funcionamento de uma sociedade em geral, principalmente no que diz respeito às ideias de segurança e bem-estar social. 
Ademais, este estudo também se enquadra no campo denominado Relações de Gênero, levando em consideração perspectivas teóricas de Joan Scott (1995), compreendendo assim uma análise de papéis sociais que são tidos como, historicamente, denominados para um gênero específico, como é o caso do homem e da mulher inseridos nas organizações da instituição Segurança Pública.

\section{METODOLOGIA}

Metodologicamente, o trabalho se deu através de um viés qualitativo, caracterizando-se enquanto uma pesquisa exploratória de materiais selecionados conforme o objetivo central. Segundo Severino (2007) uma pesquisa exploratória busca apenas levantar informações sobre um determinado objeto, delimitando assim um campo de trabalho, mapeando as condições de manifestação desse objeto. Na verdade, ela é uma preparação para uma pesquisa explicativa.

Desta forma, foram explorados e selecionados materiais que dizem respeito a inserção de mulheres na Polícia Militar do estado do Paraná (PMPR) durante a década de 1970, sendo estes representados por publicações oficiais e não oficiais de livre acesso. Além do mais, analisou-se o conteúdo da obra "Compêndio da Análise Institucional e outras vertentes: teoria e prática" de autoria de Baremblitt (2002).

Assim sendo, ao ser analisada a obra acima citada, foram relacionados conceitos referentes a Análise Institucional, em especial os conceitos de processos instituídos e processos instituintes, aos materiais que concernem à entrada de mulheres na PMPR.

Após a realização da análise de dados, os resultados referentes a este estudo teórico foram organizados, respectivamente, através de dois tópicos. O primeiro, denominado "A inserção de mulheres na Polícia Militar do Paraná: dados de um contexto histórico", enfatizará alguns dados, constando como se deu a entrada do público feminino na organização Polícia Militar no estado do Paraná em específico. Por fim, o segundo tópico, "A Polícia Feminina aos olhos de um movimento instituinte" irá relacionar os dados apresentados no primeiro tópico aos conceitos denominados processos instituídos e instituintes, que se encontram presentes no campo Análise Institucional proposto pelo teórico Baremblitt (2002).

\section{RESULTADOS E DISCUSSÃO}

\subsection{A INSERÇÃO DE MULHERES NA POLÍCIA MILITAR DO PARANÁ: DADOS DE UM CONTEXTO HISTÓRICO}


A Polícia Militar do estado do Paraná constituiu seu primeiro batalhão em 10 de agosto de 1854, estando enquadrada aos moldes da Segurança Pública (SSPAP-PR, 2019). Essa, atualmente possui mais de 60 elos que atuam transversalmente, como, por exemplo, iluminação pública, perícia forense, ministério público, entre outros. A Polícia Militar, como um todo, se divide em 27 eixos pelo Brasil, sendo correspondente um para cada estado e um para o Distrito Federal, atuando também como campo subordinado do Exército Brasileiro (Brasil, 1988). Entretanto, essa organização, como fundada no ano de 1854, se caracterizada unicamente como sendo formada por homens, assim como todos os batalhões constituintes no território brasileiro da época.

A Polícia Feminina, por sua vez, se inseriu no estado do Paraná na década de 1970, configurando-se como o segundo a abarcar Batalhões da Polícia Militar com a presença de mulheres, sendo o estado de São Paulo o primeiro, contando com a presença feminina na década de 1950.

Considerando o contexto brasileiro, a partir da década de 1930, também começaram a ocorrer reinvindicações, principalmente através dos discursos sufragistas da época, chamados de Feministas de $1^{a}$ Geração. Estas reivindicações tinham como principal pauta propor a atuação de grupos de policiamento feminino no estado de São Paulo. As mesmas pautas também foram propostas, em meados da década de 1950, em discussões elaboradas por mulheres intelectuais pertencentes à elite paulista.

No Brasil, após a conquista do voto, outros projetos de ampliação do espaço de atuação de um feminino continuaram a ser levados a cabo por mulheres. Mesmo que arrefecidos com a instalação do Estado Novo, os pressupostos do sufragismo, comumente denominado de Feminismo de 1⿳亠丷a Geração, estavam longe de extinguir-se. No caso da defesa de criação de uma polícia que fosse feminina, entenda-se maternizada, parece acertada a afirmação de June Hahner (2003, p. 31) ao se referir às sufragistas, dizendo que esse movimento garantiu legitimidade a muitas atuações de mulheres, abrindo caminho a outras reivindicações e organizações, formadas após o fim da ditadura varguista (Moreira, 2017, p. 55).

Outra circunstância que teve fortes contribuições para os debates referentes a criação de uma Polícia Feminina no âmbito brasileiro, especificamente no estado paulista, foi o contexto Pós-Guerra.

Moreira (2017) ressalta que, durante o período da Segunda Guerra Mundial, houve uma abertura para as mulheres no mercado de trabalho. Tal fato fez com que as ocupações de cargos femininos acabassem se diversificando e fortalecendo discussões acerca da inserção de mulheres em outros espaços públicos. As Organizações Femininas Auxiliares de Guerra (OFAGs), que fizeram parte do cotidiano brasileiro entre os anos 1942 a 1945, também propuseram, implicitamente, discussões sobre a implementação de uma Polícia Feminina, visto 
que as OFAGs deram espaço para que mulheres tivessem experiências com o ambiente militar, pois seguiam o modelo de estrutura do Exército do período em questão, ou seja, possuíam um rígido regulamento disciplinar.

O chamado Movimento Político Feminino (MPF), criado durante a década de 1930 no estado de São Paulo, em meados de 1940 também propôs discussões referentes à necessidade de uma Polícia composta a partir do público feminino. As mulheres participantes do MPF enfatizavam tal necessidade através do apoio a campanha da cidade de São Paulo denominada "Polícia dos Amigos da Cidade", implementado no ano de 1947 que buscava aumentar o número de policiais, vistos como amigos da cidade, visando articular uma vigilância do território urbano, prevenindo, assim, possíveis revoltas dos cidadãos.

Como argumento das participantes do MPF, a necessidade de criação de um grupo de segurança formado unicamente por mulheres dizia respeito a uma Polícia que, supostamente, não usaria a força bruta contra os habitantes da cidade de São Paulo, trabalhando com questões preventivas, como, por exemplo, policiamento preventivo e operações ostensivas direcionadas aos menores, mulheres e idosos.

Após mais de duas décadas de reivindicações, em dezembro do ano de 1955, um grupo de mulheres passaram a ser oficialmente responsáveis pela execução da atividade policial no estado de São Paulo, sendo este o primeiro do país a utilizar o policiamento feminino.

Presente de natal para São Paulo ( $A$ Hora, 26 de dez. 1955, [s.n]), mulheres militarmente perfiladas na Praça da Sé, ao som de cantos natalinos e discursos oficiais, compõe o cenário que inaugurou as atividades da "Polícia Feminina" no Brasil, na noite de 24 de dezembro de 1955. Quinze mulheres atentas aos outros e a si mesmas, defrontam-se com uma praça lotada de pessoas ouvindo o governador, Jânio Quadros, que as anunciava como presente da cidade (Moreira, 2017, p. 51).

Já no estado do Paraná, especificamente no ano de 1975, houve a aprovação da Lei de Organização Básica da Polícia Militar do Paraná, autorizando a partir do ano seguinte a previsão do ingresso de mulheres nas corporações, através da elaboração do Decreto de Lei ํㅡ 3238, em abril de 1977, instituindo-se, então, a Polícia Feminina, sendo o segundo estado a aderir a entrada da Polícia Feminina (Moreira, 2016).

Moreira (2016), ressalta que a nova categoria de Polícia, tanto no estado de São Paulo quanto no estado do Paraná, foi prevista a partir da necessidade de criação de uma denominada "nova polícia", ou seja, a partir de nossa analítica, no processo de inserção feminina na Polícia, idealizava-se a figura da mulher como sendo menos viril.

Consequentemente, isso resultaria em uma polícia mais preventiva e menos repressiva, contribuindo para a realização de tarefas específicas dentro da instituição, tais como policiamento 
preventivo e operações ostensivas ligadas a menores, estando envolta em um discurso de "humanização da polícia", visto que mulheres, naquele meio social, eram tidas como figuras de auxílio, proteção, maternidade e moral da época em questão. "A opção da corporação policial militar foi por reforçar o estereótipo feminino vinculado à essência biologicamente determinada $\mathrm{e}$ que se contrapõe à concepção de virilidade" (Moreira, 2016, p. 189).

Cabe ressaltar que a inserção de mulheres na organização da Polícia Militar do Paraná contava com uma seletividade de operações que por elas poderiam ser desempenhadas, sendo que outras operações que precisassem ser realizadas seriam executadas por homens, deixandose claro tal fato a partir da Diretriz n. 048\77, que foi instituída posteriormente a inclusão da presença feminina no batalhão, trazendo o seguinte conteúdo:

Policiamento ostensivo normal visando à guarda à segurança de estabelecimentos públicos;

Policiamento preventivo de trânsito em estabelecimentos escolares;

Ações de policiamento ostensivo relacionados à mulher, a menores e anciãos (Polícia Militar do Estado do Paraná, 1977, como citado em Moreira, 2016, p. 54).

Neste contexto, a ideia da mulher inserida dentro da organização Polícia Militar, em primeiro plano, foi assegurar um ideal de "essência feminina" a qual estava diretamente ligada a concepção de maternidade, delicadeza, cuidado e proteção, trazendo à tona, assim como enfatizado por Moreira (2016), a figura de um "anjo tutelar", para o qual as questões consideradas mais leves no âmbito da Segurança Pública seriam destinadas. (Moreira, 2016).

Assim, compreende-se como um dos eixos principais a serem problematizados, a questão dos espaços ocupados pelas mulheres enquanto sujeitos dentro da organização Polícia Militar do estado do Paraná no momento em que as mesmas foram inseridas nesse âmbito, visto que os espaços disponíveis para elas eram tidos como de profissionais "complementares" à Polícia Militar, ou seja, profissionais que estavam inseridas naquele campo para sanar necessidades que não se encaixariam no ideal de virilidade do policial masculino. Pois, homens enquanto sujeitos que foram criados para enfrentarem contextos de guerra e para serem vistos como fortes e corajosos, seriam incapazes de executar trabalhos ligados ao ideal da essência feminina.

\subsection{A POLÍCIA FEMININA AOS OLHOS DE UM MOVIMENTO INSTITUINTE}

O campo conhecido como Análise Institucional consiste em um leque de teorias e conceitos, entre eles as ideias de processos instituídos e instituintes propostos por Baremblitt (2002). Para este autor, instituinte se caracteriza como sendo um processo mobilizado por forças, 
ao mesmo tempo produtivas e desejantes, que tendem a revolucionar e fundar instituições, ou transformá-las.

Através do compartilhamento de suas potências e matérias sociais acaba por fundar novos instituídos. Processos instituídos, por sua vez, são os resultados de ações de movimentos instituintes os quais produziram cristalização de lógicas que perpassam uma instituição. Essas lógicas cristalizadas vigoram para ordenar atividades sociais essenciais para a vida em coletividade, tendo uma tendência a serem estáticas e conservadoras (Baremblitt, 2002). O instituído é necessário para a existência mínima das organizações e instituições, mas ele se cristaliza de tal modo que não permite ser representado, tendendo a falar sempre em nome de um processo dominante.

Fazendo uma discussão em relação a estes conceitos propostos, pode-se compreender a entrada de policiais femininas dentro do contexto da Polícia Militar paranaense como um movimento instituinte, ou seja, produzindo novas formas de funcionamento na organização e no funcionamento dos processos institucionais.

A identificação de ocorrências de movimentos instituintes é um convite para se pensar uma revolução nas instituições. Neste caso, o fato de que os profissionais atuantes na Polícia Militar deixaram de ser uma universalidade do sexo masculino para dar lugar a entrada de mulheres neste mesmo campo, causando uma reestruturação de tarefas e de formas de funcionamento dessa organização, como, por exemplo, a instauração de um curso de oficiais mulheres na instituição e a divisão de operações a serem realizadas por policiais homens e mulheres.

Percebe-se também que esse processo instituinte abriu lugar para uma figura antes inexistente dentro do âmbito dessa instituição: a mulher. Ao mesmo tempo em que produzia uma demanda de reconfiguração do cotidiano institucional.

Moreira (2016), compreende que o marco da entrada de mulheres como oficiais da Polícia Militar se deu através do início de um processo de ruptura com o binarismo de gênero. Gênero, por sua vez, de acordo com a autora Joan Scott (1995), é compreendido a partir de uma organização social entre os sexos, e, através desta organização, dá sentindo ao funcionamento das relações sociais humanas.

A noção de gênero se refere aos domínios estruturais e ideológicos que implicam nas relações entre os sexos. Tal preocupação, começou a ocorrer nas décadas finais do século XX, sendo considerado uma categoria de análise a partir do momento em que integrantes do movimento feminista encontraram aliados (as) cientistas e políticos (as) (Scott, 1995).

Tomando como bases teórica as discussões do filósofo Michel Foucault, Scott (1995), compreende que há linhas de pensamento em que dizem respeito a sexualidade como sendo este um conteúdo produzido através de contextos históricos distintos (Scott, 1995). "O corpo é 
construído no mundo social como realidade sexuada e como depositário de princípios de visão e divisão sexualizantes" (Moreira, 2016, p. 131).

A partir de um ideal de corpo produzido pelas distinções de funções sociais determinadas, tem-se a noção de que há a divisão social entre funções consideradas masculinas e femininas, sendo as tarefas a serem executadas por policiais militares uma delas. Há a relação de gênero na inserção da Polícia Feminina no estado do Paraná a partir do momento em que a mesma é pensada para funções desmilitarizadas, ou seja, voltada ao cuidado ao outro (Moreira, 2016).

Em contrapartida, é necessário abarcar que as lógicas constituintes de processos instituídos e instituintes se perpassam, havendo uma transversalidade dessas lógicas as quais se encontram cristalizadas e, ao mesmo tempo, em constante movimento. Visto isso, é possível fazer um ressalvo que, mesmo que com todas as mudanças inseridas pelo movimento instituinte proposto pela entrada de mulheres na organização Polícia Militar, também houve a reprodução de lógicas instituídas dentro desse mesmo contexto, havendo assim uma contraposição entre instituído e instituinte.

Uma das lógicas que se mantiveram, a partir deste processo, foi a questão do corpo militarizado estar voltado para a ideia de disciplina. As mulheres inseridas na instituição militar em questão, assim como os homens, também deveriam cumprir leis que propunham um padrão de comportamento que dava manutenção há um controle disciplinar estruturado e estruturador de seu ambiente de trabalho. Entretanto, esses comportamentos eram diferenciados para, mais uma vez, reafirmarem uma produção de binarismo de gênero onde o masculino era visto como superior ao feminino.

Excluídas da memória e da tradição institucional, as quais afirmam um ideal de masculinidade no culto aos heróis, as policiais femininas, assim nomeadas para marcar mais uma diferença nas identificações que existem no espaço institucional, precisam assumir o comportamento feminino definido pela legislação. Para serem reconhecidas como agentes institucionais honradas, deveriam assumir publicamente um comportamento qualificado para uma policial feminina (Schactae, 2015, p. 4).

Vale destacar um fragmento da diretriz no 046\77, cujas competências dizem respeito exclusivamente aos comportamentos femininos que estariam sujeitos a punição dentro da instituição:

a. Comprometer-se irregularmente com encargos de família; b. fazer-se acompanhar, quando uniformizada, salvo se estiver em missão ou serviço; c. frequentar, uniformizada, cafés, bares ou estabelecimentos similares, salvo em missão ou serviço; $d$. frequentar, quando uniformizada, cinemas, teatros, casas de diversão e similares, salvo em missão ou serviço; e. fumar em serviço, estando uniformizada ou não; f. manter relacionamento ou amizade com pessoas de reputação duvidosa; g. receber visitas nos 
postos de serviço ou interior do aquartelamento; $h$. usar, quando uniformizada, cabelos compridos, de cor diferente do natural, com penteados exagerados, perucas, maquilagem excessiva, unhas longas ou com verniz de cor (Polícia Militar do Estado do Paraná, 1977, como citado em Moreira, 2016 p. 71).

Assim, as mulheres, no contexto da Polícia paranaense deveriam estar ligadas a lógica disciplinar voltada ao contexto da organização militar, também deixando transparecer que havia uma diferenciação em relação aos homens, com regras e diretrizes exclusivas para as policiais, em que elas reproduziam a gestão de seus comportamentos do ser policiais femininas, evidenciando o entrelaçamento entre os processos instituídos e instituintes na Polícia Militar.

\section{CONSIDERAÇÕES FINAIS}

Ponderando a concepção de Schactae (2015), evidenciam-se as lógicas transversalizadas pelos movimentos instituídos e instituintes pela inclusão de mulheres na Polícia Militar do estado do Paraná

Vale destacar que

"a Polícia Feminina foi ao mesmo tempo uma inovação - a instituição deixou de ser exclusividade dos homens - e uma afirmação da tradição, pois sua existência reafirma o domínio masculino. É a partir da relação entre a inovação e a tradição que foi instituída a Polícia Militar Feminina como um lugar de contradição" (Schactae, 2015, p. 3).

Apesar de esse movimento ter se construído inicialmente através dos moldes de um movimento instituinte, propondo, de certo modo, uma revolução dentro da instituição, algumas lógicas instituídas ainda se mantiveram como iguais, ou até mesmo maior intensidade dentro desse movimento que acabava de ser instaurado. Entre o que se manteve, certamente está a da compreensão de uma suposta superioridade da figura masculina dentro da instituição, alimentada pela categoria social de virilidade. Breattie (2004) como citado em Schactae, (2015) ressalta que o ideal de uma identidade militar foi composto em meados do século XX no Brasil, tendo em vista a construção de uma masculinidade controlada, que, por sua vez, visava a virilidade

A instituição Segurança Pública, a qual enquadra a organização Polícia Militar em seu entorno, é atravessada por outras instituições que se configuram entre si a todo momento, não deixando, assim, que as instituições prevaleçam de uma forma estática, estando também nessas instituições regras instituídas que são compostas por lógicas cristalizadas, que, por sua vez, são estáticas, havendo assim uma ambivalência de lógicas. Dentre elas, comporta-se a questão de Rev. Psicol Saúde e Debate. Jul., 2019:5(1):132-143. 
um binarismo de gênero, o qual produz a concepção de uma visão do masculino enquanto viril, ligado a coragem e a luta, se sobressaindo ao feminino, que é ligado a uma fragilidade, maternidade e cuidado.

O trabalho em questão teve o intuito de apresentar alguns conceitos ligados ao campo da psicologia chamado Análise Institucional, tais conceitos formulados por Gregório Baremblitt, sustentaram a análise sobre a forma como a qual se deu a admissão da Polícia Feminina no estado do Paraná, considerando também seu contexto histórico. Assim, compreendeu-se a entrada de mulheres na organização Polícia Militar do Paraná como uma desconstrução de modelos pré-estabelecidos, como a concepção de uma organização como sendo unicamente masculina, cujos trabalhos dos policiais deveriam ser executados apenas por profissionais do sexo masculino, modificando assim algumas lógicas as quais estavam cristalizadas na mesma. Por outro lado, a reprodução de um discurso masculino dominante continua em evidência, propondo uma divisão de funções de gênero.

Neste contexto, cabe uma problematização para trabalhos subsequentes sobre como se deu as posteriores configurações do campo de forças da permanência de mulheres na Polícia Militar Feminina do Paraná até nos dias de hoje. Esse processo continuaria sendo posto como instituinte ou está totalmente inserido em lógicas cristalizadas instituídas? Como essa questão se compreende no contexto do cenário contemporâneo? Essas são problematizações que foram provocadas através da análise de um contexto histórico no campo da Segurança Pública e que se enquadram em pontos de discussões para possíveis estudos posteriores.

\section{REFERÊNCIAS}

Baremblitt, G. (2002). Compêndio de análise institucional e outras correntes: teoria e prática. Belo Horizonte: Instituto Felix Guattari.

Beattie, P. (2004). Ser homem pobre, livre e honrado: a sodomia e os praças nas Forças Armadas brasileiras (1860-1930). In: Castro, C., Izeckson, V. \& Kraay, H. Nova história militar brasileira. Rio de Janeiro: Editora FGV, 269-299.

Constituição da República Federativa do Brasil de 1988. (1998). Brasília. Recuperado em 03 de novembro de 2018, de http://www.planalto.gov.br/ccivil_03/Constituicao/Constituicao.htm.

Hahner, J. E. (2003) Emancipação do sexo feminino: a luta pelos direitos da mulher no Brasil, 1850-1940. Florianópolis: Editora Mulheres.

Decreto $n$. 3238, de 20 de abril de 1977 (1977). O GOVERNADOR DO ESTADO DO PARANÁ, no uso das atribuições que lhe são conferidas pelo Art. 47, item II, da Constituição Estadual e o que dispõe o artigo 57 da Lei no 6.774, de 08 de janeiro de 1976. Governo do Paraná, PR. Recuperado em 16 de novembro de 2018, de http://celepar7cta.pr.gov.br/seap/legrhv1.nst/03c8822a9a6b69bb03256d3c006690af/44aef7f5540d10eb03256abc006ad968?Ope nDocument ). 
Diretriz no $046 \mid 77$ (1977). CFAP. Procedimentos para o Curso de Formação de Sargentos Femininos, de dezembro de 1977. Polícia Militar do Paraná.

Diretriz no $048 \mid 77$ (1977). 3ํㅗeção do Estado Maior, de dezembro de 1977. Emprego da Polícia Feminina. Polícia Militar do Paraná.

Hur, D. U. (2014). Trajetórias de um pensador nômade: Grogório Baremblitt. Estudos e Pesquisas em Psicologia. 14(3). Universidade Federal de Goiás - UFG. Recuperado de http://www.e-publicacoes.uerj.br/index.php/revispsi/article/view/13899/10585. Acesso em: 02 de abril de 2018.

L'abbate, S. (2003). A análise institucional e saúde coletiva. Ciência e Saúde Coletiva. 8(1), 265274. Recuperado de http://www.scielo.br/pdf/csc/v8n1/a19v08n1.pdf. Acesso em 02 de abril de 2018.

Moreira, R. A invenção da mulher policial militar do Paraná (2016). In: Moreira, R. \& Schactae, A. M. (Orgs.). Gênero e instituições armadas. Guarapuava: Editora UNICENTRO.

Moreira, R. (2016). Entre o mito e modernidade: a entrada de mulheres na Polícia Militar do Paraná. Guarapuava: Editora UNICENTRO.

Moreira, R. (2017). Sobre mulheres e Polícias: Polícia feminina no Brasil - a invenção paulista (1955-1964). Guarapuava: Editora UNICENTRO.

Schactae, A. M. (2015). A ordem e a margem: comportamento disciplinar para Polícia Feminina no Paraná (1977-2000). Revista Tempo. 21(37), 01-21. Recuperado de: http://www.scielo.br/pdf/tem/v21n37/1413-7704tem-21-37-00001.pdf. Acesso em 05 de novembro de 2018.

Scott, J. W. (1995). Gênero: uma categoria útil de análise histórica. Educação \& Realidade. 20(2), 71-99.

Severino, A. J. (2007). Metodologia do trabalho científico. São Paulo: Cortez.

SSPAP-PR, Secretaria da Segurança Pública e Administração Penitenciária - Governo do Estado do Paraná. Institucional: Histórico. Recuperado de: http://www.pmpr.pr.gov.br/modules/conteudo/conteudo.php?conteudo=3 . Acesso em 10 de janeiro de 2019. 